\title{
HLA class II genes associated with anticentromere antibody in Japanese patients with systemic sclerosis (scleroderma)
}

\author{
Masataka Kuwana, Yutaka Okano, Junichi Kaburaki, Hidetoshi Inoko
}

\begin{abstract}
Objective-To define further HLA class II gene associations with anticentromere antibody (ACA), a major serum antinuclear antibody in patients with systemic sclerosis (SSc).

Methods-HLA class II genes were determined using polymerase chain reaction/ restriction fragment length polymorphisms in 94 Japanese patients with SSc (22 ACA positive and 72 ACA negative) and 50 race matched normal control subjects.

Results-Frequency of DQB1*0501 was increased in ACA positive SSc patients compared with ACA negative SSc patients $(36 \%$ versus $13 \% ; p=0.02$, odds ratio $=4 \cdot 0$, $95 \%$ confidence interval $1 \cdot 1$ to 13.9$)$, but the association of ACA with a polar amino acid at position 26 in the DQB1 $\beta 1$ domain, which was demonstrated in white North Americans, was not observed in Japanese. The DRB1*0101, $\star_{0405}$, and $\star 1302$ alleles were associated with high ACA titres, whereas DRB1 ${ }^{\star} 1502$ was associated with low ACA titres and a low frequency of centromere protein $C$ (CENP-C) reactivity.
\end{abstract}

Conclusions-These results suggest that the ACA response is associated with multiple HLA class II genes and that ACA positive SSc patients are heterogeneous in terms of immunogenetic background.

(Ann Rheum Dis 1995; 54: 983-987)

It is well known that many autoimmune diseases are associated with certain HLA types. Systemic sclerosis (or scleroderma) (SSc) is an autoimmune disease characterised by fibrosis of the dermis and internal organs and microvascular damage. ${ }^{1}$ However, previous studies have failed to detect any reproducible HLA associations with $\mathrm{SSc}{ }^{2}$ presumably because of the heterogeneity of the disease. Recent molecular analyses of genes encoding HLA class II molecules have revealed that HLA class II genes are associated more closely with each SSc related serum antinuclear antibody (ANA) than with the disease itself. For example, the presence of antibody to DNA topoisomerase I (topo I) is associated with $\mathrm{DRB} 1^{\star} 1502$ and $\mathrm{DQB} 1^{\star} 0601$ in Japanese, and broad specificities of DQ3 (DQB1 $\left.{ }^{\star} 0301{ }^{\star}{ }^{\star} 0303\right)$ in black and white North Americans. ${ }^{34}$

Anticentromere antibody (ACA) is one of the major SSc related serum ANAs and is detected in about $20 \%$ of SSc patients from various ethnic backgrounds. ${ }^{5}$ ACA occurs in a relatively homogeneous SSc subset having limited cutaneous SSc or the CREST variant (calcinosis, Raynaud's phenomenon, oesophageal dysmotility, sclerodactyly, telangiectasia). ${ }^{1}$ ACA in SSc sera mainly recognise three major centromere constituent proteins (CENP) of molecular weights $16 \mathrm{kDa}$ (CENP-A), $80 \mathrm{kDa}$ (CENP-B), and $140 \mathrm{kDa}$ (CENP-C). ${ }^{6}$ Increased frequencies of HLA-DR1, -DR4, and -DR8 have been detected in SSc patients with ACA by serological HLA typing. ${ }^{7}$ The association of ACA with DR1 and DR4 was confirmed by a recent study using molecular HLA typing. ${ }^{9}$ Another study using restriction fragment length polymorphism analysis of genomic DNA reported increased frequencies of DR11 and DQ7 (DQB1*0301) in patients with the CREST variant, the majority of whom were considered to have ACA. ${ }^{10} \mathrm{~A}$ large study using HLA class II genotyping showed that all the 42 ACA positive SSc patients, compared with $69 \%$ of ACA negative SSc patients and $71 \%$ of race matched normal control subjects, had at least one DQB1 allele with a polar amino acid (glycine or tyrosine) at position 26 in the $\beta 1$ domain, which is shared by $\mathrm{DQB} 1^{\star} 0501$ ${ }^{\star} 0504,{ }^{\star} 0601,{ }^{\star} 0301,{ }^{\star} 0401$, and ${ }^{\star} 0402 .{ }^{11}$ This DQB1 gene association was confirmed by one study analysing HLA class II alleles in ACA positive SSc patients and their relatives, ${ }^{12}$ but not by another study. ${ }^{13}$

In this study, we analysed the HLA class II gene associations with ACA in Japanese patients with SSc. We also examined HLA associations with ACA titres and immunoreactivities against individual CENP (CENP-A, -B, and $-\mathrm{C})$.

Patients and methods

PATIENTS AND CONTROLS

We studied 94 unrelated Japanese SSc patients who were seen for evaluation between October 1992 and April 1993 at either Keio University School of Medicine (Tokyo) (90 patients) or Nippon Kokan Hospital (Kawasaki, adjacent to Tokyo) (four patients). All satisfied the American College of Rheumatology (formerly the American Rheumatism Association) preliminary classification criteria for SSc. ${ }^{14}$ Nineteen, 54, and 21 patients were classified as having diffuse cutaneous SSc, limited cutaneous SSc, and SSc overlap variant, respectively, according to the classification described by Medsger. ${ }^{1}$ Twenty one patients with SSc
Bittsburgh, PA 15213, USA.

Accepted for publication 31 August 1995 
overlap included six with SSc-systemic lupus erythematosus (SLE), seven with SScpolymyositis (PM), three with SSc-rheumatoid arthritis (RA), four with SSc-SLE-PM, and one with SSc-PM-RA. Fifty healthy Japanese volunteers living in the Tokyo-Kawasaki area were selected as race matched normal control subjects.

\section{ANA ASSAYS}

Serum samples for analysis were obtained from all SSc patients at the time of their first visit and stored at $-20^{\circ} \mathrm{C}$. To identify SSc related ANAs, we performed indirect immunofluorescence on commercially available HEp-2 cell slides and HeLa cell chromosomal spread slides (MBL, Nagano, Japan), double immunodiffusion using calf and rabbit thymus extract as an antigen, and immunoprecipitation assays using ${ }^{32} \mathrm{P}$ - and ${ }^{35} \mathrm{~S}$-labelled $\mathrm{HeLa}$ cell extracts as described elsewhere. ${ }^{15}$ ACA was defined as positive if immunofluorescence using serum samples at a dilution of 1:40 showed a discrete speckled pattern consistent with ACA on HEp-2 cells, and two small spheres located on the centromeric region of each chromosome on HeLa cell chromosomal spreads. ${ }^{16}$ Serum ACA titres were determined by indirect immunofluorescence on chromosomal spreads using twofold serial dilutions of sera ranging from 1:200 to 1:6400. Immunoreactivities against CENP-A, $-\mathrm{B}$, and $-\mathrm{C}$ were examined in ACA positive sera by immunoblots using mitotic chromosomes from colcemid arrested HeLa cells as antigens. ${ }^{17}$ Briefly, $\mathrm{HeLa}$ mitotic chromosomes were resolved on $11 \%$ polyacrylamide-sodium dodecyl sulphate gels and transferred onto nitrocellulose filters. The filters were then probed with sera diluted at 1:500 and subsequently with horseradish peroxidase conjugated goat antihuman IgG (Fcy specific, GIBCO BRL, Grand Island, NY). Immunoreactivities were visualised using a chemiluminescence detection system (DuPont NEN, Boston, MA).

HLA CLASS II ALLELE TYPING

The HLA-DRB1, -DQB1, and -DPB1 genes were typed using restriction fragment length polymorphisms of polymerase chain reaction amplified genomic DNA as described previously..$^{18}$ The numbers of alleles defined by this method are 44 (DRB1), 13 (DQB1), and 19 (DPB1).

\section{STATISTICAL ANALYSIS}

Differences in frequencies were analysed by Fisher's two tailed exact test. Corrected $\mathrm{p}$ values were obtained by multiplying observed $p$ values by the number of comparisons made $(\mathrm{DRB} 1 \times 44, \mathrm{DQB} 1 \times 13$, and $\mathrm{DPB} 1 \times 19)$. When an association with a particular specificity had been reported previously, the $p$ value was not corrected. ${ }^{11}$ The odds ratio (OR) with a $95 \%$ confidence interval $(95 \% \mathrm{CI})$ of the significant differences was calculated, and when one of the four cells of the $2 \times 2$ tables was 0 , Haldane's modification was applied.

\section{Results}

Twenty two (23\%) of 94 SSc patients were identified as having ACA. Coexistence of other SSc related ANAs in ACA positive SSc patients was infrequent; only one had antibody to Th ribonucleoprotein (RNP). All 22 ACA positive patients were classified as having limited cutaneous SSc. Among 72 ACA negative SSc patients, anti-U1 RNP was detected in 34, anti-topo $I$ in 30, anti-RNA polymerase in four, anti-Th RNP in four, anti-U3 RNP (fibrillarin) in three, and anti-Ku in three. The distribution of SSc related ANAs was similar to that reported in our previous study involving 275 unselected Japanese patients with SSc. ${ }^{5}$

We could not find any statistically significant differences in HLA-DR allele frequencies when HLA class II gene frequencies in 22 ACA positive patients were compared with those in 72 ACA negative patients and in 50 normal control subjects. However, DR1 (DRB1*0101) was more frequent in ACA positive patients than in ACA negative patients and normal controls (32\% versus $13 \%$ and $12 \%, \mathrm{p}=0.051$ and 0.09 , respectively). In contrast, there were trends toward lesser frequencies of DR5 (all combined DRB1*1101, *1102, * 1201 , and $\left.{ }^{\star} 1202\right)$ and DR9 (DRB1 $\left.{ }^{\star} 0901\right)$ in ACA positive patients compared with the other two groups ( $5 \%$ versus $19 \%$ and $16 \%$; and $9 \%$ versus $24 \%$ and $30 \%$, respectively). When DQB1 allele frequencies were compared between ACA positive SSc patients and ACA negative SSc patients or healthy controls (table 1), DQB $1{ }^{\star} 0501$ was more frequent in ACA positive patients than in ACA negative patients $(p=0 \cdot 02)$. There were

Table $1 \quad H L A-D Q B 1$ and DPB1 allele frequencies in 94 fapanese patients with systemic sclerosis (SSc) with or without anticentromere antibody $(A C A)$, and 50 race matched normal controls

\begin{tabular}{|c|c|c|c|}
\hline Alleles & $\begin{array}{l}\text { SSc patients } \\
\text { with } A C A \\
(n=22)\end{array}$ & $\begin{array}{l}\text { SSc patients } \\
\text { without } A C A \\
(n=72)\end{array}$ & $\begin{array}{l}\text { Normal } \\
\text { controls } \\
(n=50)\end{array}$ \\
\hline DQB1*0501 & $8(36)^{\star}$ & $9(13)$ & $8(16)$ \\
\hline DQB $1{ }^{\star} 0502$ & $2(9)$ & $3(4)$ & $3(6)$ \\
\hline $\mathrm{DQB} 1{ }^{\star} 0503$ & $1(5)$ & $2(3)$ & $8(16)$ \\
\hline $\mathrm{DQB} 1{ }^{\star} 0601$ & $9(41)$ & $39(54)$ & $18(36)$ \\
\hline $\mathrm{DQB} 1{ }^{\star} 0602$ & $2(9)$ & $3(4)$ & $5(10)$ \\
\hline $\mathrm{DQB} 11^{\star} 0604$ & $4(18)$ & $4(6)$ & $7(14)$ \\
\hline $\mathrm{DQB} 1{ }^{\star} 0301$ & $1(5) \dagger$ & $19(26)$ & $13(26)$ \\
\hline DQB $1{ }^{\star} 0302$ & $6(27)$ & $22(31)$ & 7 (14) \\
\hline $\mathrm{DQB} 1{ }^{\star} 0303$ & $2(9) \ddagger$ & $16(22)$ & $16(32)$ \\
\hline$D Q B 1^{\star} 0401$ & $5(23)$ & 9 (13) & $10(20)$ \\
\hline $\mathrm{DQB} 1^{\star} 0402$ & $1(5)$ & $5(7)$ & $4(8)$ \\
\hline DPB1*0201 & $4(18)$ & $18(25)$ & $18(36)$ \\
\hline $\mathrm{DPB} 1 \star 0202$ & $4(18)$ & $2(3)$ & $5(10)$ \\
\hline$D P B 1 \star 0301$ & $1(5)$ & $11(15)$ & $5(10)$ \\
\hline DPB1*0401 & $1(5)$ & $2(3)$ & $4(8)$ \\
\hline DPB $1 \star 0402$ & $12(55) \S$ & $15(21)$ & $11(22)$ \\
\hline DPB $1 \star 0501$ & $11(50)$ & 39 (54) & $30(60)$ \\
\hline DPB $1 \star 0901$ & $5(23)$ & $33(46)$ & $8(16)$ \\
\hline $\mathrm{DPB} 11^{\star} 1301$ & 0 & $1(1)$ & $2(4)$ \\
\hline DPB $1 * 1401$ & 0 & 1 (1) & 0 \\
\hline
\end{tabular}

Values are number $(\%)$

${ }^{\star} \mathrm{p}=0.02, \mathrm{OR}=4.0(95 \% \mathrm{CI} 1.1$ to 13.9$)$ compared with SS patients without ACA; tp $=0.04$, OR $=0.13(95 \%$ CI 0.0 to 1.0 ) compared with SSc patients without ACA, and $p=0.050$ $\mathrm{OR}=0.14(95 \% \mathrm{CI} 0.0$ to 1.1$)$ compared with normal controls $\neq \mathrm{p}=0.04, \mathrm{OR}=0.21(95 \% \mathrm{CI} 0.02$ to 1.1$)$ compared with normal controls. $\mathrm{p}=0.005, \mathrm{OR}=4.6(95 \% \mathrm{CI} 1.5$ to 14.2$)$ compared with SSc pation without $A$, compared with SSc patients without ACA, and $p=0.01$ OR $=4 \cdot 3$ 
trends toward negative associations of ACA with $\mathrm{DQB} 1{ }^{\star} 0301$ and $\mathrm{DQB} 1{ }^{\star} 0303$. The frequency of $\mathrm{DPB} 1{ }^{\star} 0402$ was greater in ACA positive patients compared with ACA negative patients and normal control subjects $(p=0.005$ and 0.01 , respectively), but this difference did not reach statistical significance after correlation of the $\mathrm{p}$ value. The DQB1 alleles having a polar amino acid at position 26 , which were reported to be essential for the ACA response in white North American patients, ${ }^{11}$ were found in all except one ACA positive patients (95\%), compared with $63(88 \%)$ of 72 ACA negative patients (NS) and $44(88 \%)$ of 50 normal controls (NS).

As all 22 ACA positive patients were classified as having limited cutaneous SSc, HLA class II gene frequencies in ACA positive SSc patients were compared with those in 32 ACA negative patients with limited cutaneous SSc. Frequencies of $\mathrm{DQB} 1{ }^{\star} 0501$ and $\mathrm{DPB} 1{ }^{\star} 0402$ were again greater $(36 \%$ versus $13 \%, p=0.050, O R=4.0,95 \%$ CI 0.9 to 20.9 ; and $50 \%$ versus $22 \%, p=0.01, O R=4.3,95 \%$ CI $1 \cdot 1$ to $16 \cdot 7$, respectively) and that of DQB $1{ }^{\star} 0301$ was again less $(5 \%$ versus $38 \%$, $\mathrm{p}=0.008, \mathrm{OR}=0.08,95 \%$ CI 0.0 to 0.7 ) in ACA positive compared with ACA negative patients with limited cutaneous SSc. Exclusion of 21 patients with SSc overlap did not influence the HLA-ACA associations described above (data not shown).

Table 2 summarises the DRB1 alleles, and the ACA titres and reactivities against CENP-A, -B, and -C, in 22 ACA positive SSc patients. ACA titres ranged from 200 to $\geq 6400$. When they were separated into high ACA titres $(n=14, \geq 1600)$ and low ACA titres $(\mathrm{n}=8,<1600)$, six of seven patients having $\mathrm{DRB} 1{ }^{\star} 0101$, four of five patients having DRB $1^{\star} 0405$, and all four patients having DRB $1 * 1302$ were included in the high ACA titre group. One of these three alleles was detected in $13(93 \%)$ of 14 patients with high ACA titres, compared with two (25\%) of eight patients with low ACA titres $(p=0.002$, $\mathrm{OR}=39,95 \%$ CI $2 \cdot 1$ to 1924$)$. In contrast, five of six patients possessing $\mathrm{DRB} 1{ }^{\star} 1502$ were included in the low ACA titre group, and the remaining one $\mathrm{DRB} 1{ }^{\star} 1502$ positive patient, whose ACA titre was 3200 , had DRB1*1302. Therefore, the frequency of DRB1* 1502 in patients with high ACA titres $(7 \%)$ was significantly lower than that in patients with low ACA titres $(68 \% ; p=0.01$, $\mathrm{OR}=0.05,95 \%$ CI 0.0 to 0.7 ). No significant associations between ACA titres and DQB1 and DPB1 alleles were found.

CENP-A, -B, and -C were recognised by 22 $(100 \%), 22(100 \%)$, and $19(86 \%)$ sera, respectively. All three patients negative for CENP-C reactivity had DRB1* 1502 , and CENP-C reactivity was detected in only three $(50 \%)$ of six patients with DRB1* 1502 compared with all 16 patients lacking DRB1 1502 $(p=0.01$, OR $=0.03,95 \%$ CI 0.0 to 0.7$)$. $\mathrm{DQB1}{ }^{\star} 0601$ in linkage disequilibrium with DRB1* 1502 is probably not responsible for this negative association with CENP-C reactivity, as sera from all three ACA positive patients possessing $\mathrm{DRB} 1^{\star} 0803$ (another major DRB1 allele that links to $\mathrm{DQB} 1^{\star} 0601$ in Japanese) were reactive with CENP-C.

\section{Discussion}

We examined HLA-DRB1, -DQB1, and -DPB1 gene associations with ACA in Japanese patients with SSc. To minimise patient selection bias, we recruited all patients seen in clinic during a period of seven months. As a result, the number of ACA positive SSc patients was relatively small $(n=22)$; however, we believe that the possible consequent bias does not affect our conclusion, as ANA distribution in the present study was similar to that in unselected SSc patients in our previous study. ${ }^{5}$ DQA1 was not examined in this study because of strong linkage disequilibrium between DQA1 and DQB1 genes. Our results can be summarised as follows: the presence of ACA was associated with $\mathrm{DQB} 1{ }^{\star} 0501$; a low frequency of CENP-C reactivity was associated with $\mathrm{DRB} 1{ }^{\star} 1502$; high ACA titres were

Table 2 Anticentromere antibody (ACA) titres and reactivities against three centromere constituent proteins (CENP-A, $-B$, and $-C$ ) in $22 A C A$ positive SSc patients, and their DRB1 alleles

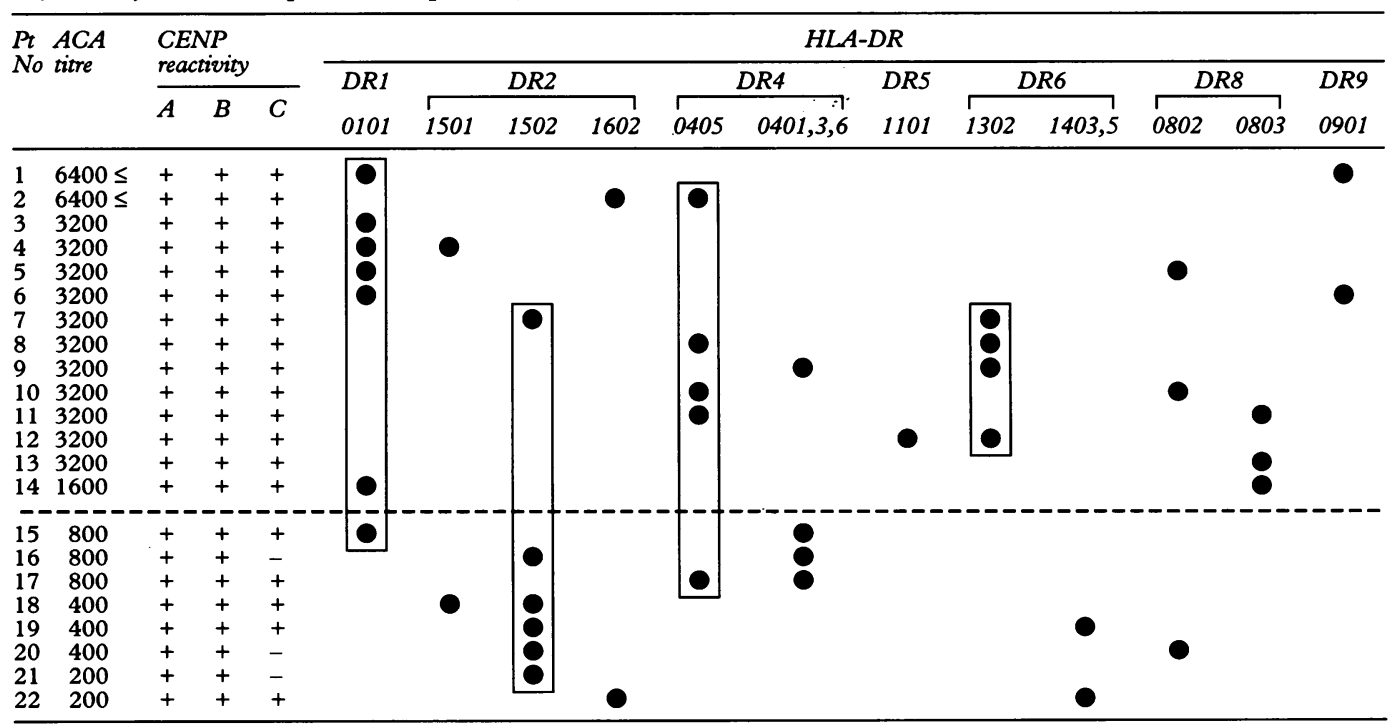


positively associated with $\mathrm{DRB} 1^{\star} 0101$, $\mathrm{DRB} 1{ }^{\star} 0405$, and DRB1*1302, and negatively associated with $\mathrm{DRB} 1^{\star} 1502$. These results suggest that the ACA response is associated with several alleles located on HLA-DR and $-D Q$ genes, though some of the associations could be explained by the known linkage disequilibrium between DRB1 and DQB1. Furthermore, our data indicate that HLA class II genes regulate antibody responses by means of antibody titres and immunoreactivities against the constituent proteins. This immune regulatory mechanism is analogous to that of other SSc related ANAs (including anti-topo I and anti-U1 RNP responses) that we have shown previously. ${ }^{3} 19$

We examined the HLA associations with reactivities to CENP, but only a borderline association with CENP-C reactivity was detected. One possible reason for the weak associations is high frequencies of CENP-A, -B, and $-C$ reactivities in ACA positive SSc patients; all ACA positive sera recognised CENP-A and -B, and 19 of 22 sera were reactive with CENP-C. Further study including a large number of ACA positive patients is necessary to confirm possible associations between HLA class II alleles and reactivities to CENP. We have shown previously that reactivities against different B cell epitopes on the topo I molecule were associated with different HLA-DR specificities. ${ }^{3}$ As CENP were suggested to carry multiple epitopes recognised by patients' sera, ${ }^{20}$ detailed analyses of $\mathrm{B}$ cell epitopes on the CENP are helpful in further defining HLA class II gene associations with ACA.

Previous studies analysing HLA associations with ACA proposed that the HLA-DQ genes primarily regulate ACA responses based on shared amino acid sequences that are present in the DQB1 alleles associated with ACA. ${ }^{11}{ }^{13}$ Reveille et al reported that ACA was associated with $\mathrm{DQB} 1{ }^{\star} 0501$ and ${ }^{\star} 0301$ in white North Americans and that the DQB1 alleles possessing a polar amino acid at position 26 were detected in all ACA positive SSc patients examined. ${ }^{11}$ The increased frequency of DQB1*0501 in ACA positive SSc patients is consistent with our results, whereas the frequency of $\mathrm{DQB} 1{ }^{\star} 0301$ was decreased in ACA positive SSc patients in this study. Furthermore, we did not detect an association between ACA and a polar amino acid at position 26 in the $\beta 1$ domain of DQB1. It is unlikely that these differences between Reveille's results and ours reflect ethnic or geographic differences between the respective subjects studied, as Morel et al, analysing the same North American population as was examined by Reveille, also reported that $10(21 \%)$ of 47 ACA positive SSc patients lacked the polar amino acid at position 26 in the DQB1 genes. ${ }^{13}$ Morel's group described, instead, an increased frequency of the TRAELDT sequence at amino acids 71-77 of the DQB1 chain in ACA positive SSc patients compared with ACA negative SSc patients lacking $\mathrm{DQB} 1^{\star} 0501(78 \%$ versus $62 \%) .{ }^{13}$ However, the association of ACA with the TRAELDT sequence in DQB ${ }^{\star} 0501$ negative individuals was not confirmed in our study, because the TRAELDT sequence was detected in $13(93 \%)$ of 14 ACA positive SSc patients, but also in all 63 ACA negative SSc patients and $39(93 \%)$ of 42 normal controls, who did not possess DQB1*0501 (data not shown). In common with these recent studies, our present report suggests that ACA responses cannot be explained by the shared amino acid sequences present in the DQB1 genes.

We have shown instead, that high ACA titres are associated with multiple DRB1 alleles, including $\mathrm{DRB} 1{ }^{\star} 0101,{ }^{\star} 0405$, and ${ }^{\star} 1302$. These DRB1 alleles do not have shared amino acid sequences in the antigen binding domain. Our recent studies of $T$ cells reactive with topo I revealed that distribution of $\mathrm{T}$ cell epitopes on topo I had an association with the nature of the patient's HLA-DR alleles, ${ }^{22}$ suggesting that each $T$ cell epitope is restricted by distinct HLA-DR alleles. Although to date there are no reports describing $T$ cell responses to centromere proteins, it is possible that several $\mathrm{T}$ cell epitopes are present on the centromere antigen complex and that each $T$ cell epitope is restricted by different HLA class II molecules.

We thank $\mathrm{Dr}$ Carol A Feghali for critical review of this manuscript, Tadayuki Sato and Kaoru Sato for technical assistance in HLA typing, and Claudia Conte for assisting with the statistical analysis. This work was supported by the Scleroderma Grant for Intractable Disease from the Japanese Ministry of Health and Welfare, and Grants-in-aid from the Japanese Ministry of Education, Science and Culture.

1 Medsger T A Jr. Systemic sclerosis (scleroderma), localized forms of scleroderma, and calcinosis. In: D J McCarty, W J Koopman, eds. Arthritis and allied conditions. Philadelphia: Lea \& Febiger, 1993; 1253-92.

2 Reveille J D. Molecular genetics of systemic sclerosis. Cur Opin Rheumatol 1993; 5: 753-9.

3 Kuwana M, Kaburaki J, Okano Y, Inoko H, Tsuji K. The HLA-DR and DQ genes control the autoimmun response to DNA topoisomerase $I$ in systemic sclerosis (scleroderma). F Clin Invest 1993; 92: 1296-301.

4 Reveille J D, Durban E, MacLeod-St Clair M J, et al. Association of amino acid sequences in the HLA-DQB1 first domain with the antitopoisomerase I autoantibody response in scleroderma (progressive systemic sclerosis) r Clin Invest 1992; 90: 973-80

5 Kuwana M, Okano Y, Kaburaki J, Tojo T, Medsger T A Jr Racial differences in the distribution of systemic sclerosisrelated serum antinuclear antibodies. Arthritis Rheum 1994; 37: 902-6.

6 Earnshaw W C, Bordwell B J, Marino C, Rothfield N F Three human chromosomal autoantigens are recognized by sera from patients with anti-centromere antibodies. f Clin Invest 1986; 77: 426-30.

7 Genth E, Mierau R, Genetzky P, et al. Immunogenetic associations of scleroderma-related antinuclear antibodies. Arthritis Rheum 1990; 33: 657-65.

8 Steen V D, Powell D L, Medsger T A Jr. Clinical correlations and prognosis based on serum autoantibodies with systemic sclerosis. Arthritis Rheum 1988; 31: 196-203.

9 Briggs D, Stephens C, Vaughan R, Welsh K, Black C. A molecular and serologic analysis of the major histocompatibility complex and complement component $\mathrm{C} 4$ in systemic sclerosis. Arthritis Rheum 1993; 36: 943-54.

10 Dunckley H, Jazwinska E C, Gatenby P A, Serjeantson S W. DNA-DR typing shows HLA-DRw11 RFLPs are increased in frequency in both progressive systemic sclerosis and CREST variants of scleroderma. Tissue Antigens 1989; 33: 418-20.

11 Reveille JD, Owerbach D, Goldstein R, Moreda R, Isern RA, Arnett F C. Association of polar amino acids at position 26 of the HLA-DQB1 first domain with the anticentromere autoantibody response in systemic sclerosis (scleroderma). $\mathcal{F}$ Clin Invest 1992; 89: 1208-13.

12 McHugh N J, Whyte J, Arlett C, et al. Anti-centromere antibodies (ACA) in systemic sclerosis patients and their relatives: a serological and HLA study. Clin Exp Immuno 1994; 96: 267-74

13 Morel P A, Chang H J, Wilson J W, et al. HLA and ethnic associations among systemic sclerosis patients with anticentromere antibodies. Hum Immunol 1995; 42: 35-42.

14 Subcommittee for Scleroderma Criteria of the American Rheumatism Association Diagnostic and Therapeutic Criteria Committee. Preliminary criteria for the classification of systemic sclerosis (scleroderma). Arthritis Rheum 1980; 23: 581-90.

15 Kuwana M, Kaburaki J, Okano Y, Tojo T, Homma M Clinical and prognostic associations based on serum 
antinuclear antibodies in Japanese patients with systemic sclerosis. Arthritis Rheum 1994; 37: 75-83.

16 Moroi Y, Peebles C, Fritzler M J, Steigerwald J, Tan E M. Autoantibody to centromere (kinetochore) in scleroderma sera. Proc Natl Acad Sci USA 1980; 77: 1627-31.

17 Bernet R L, Borisy G G, Rothfield N F, Earnshaw W C. Injection of anticentromere antibodies in interphase disrupts events required for chromosome movement at mitosis. F Cell Biol 1990; 111: 1519-33.

18 Inoko H, Ota M. PCR-RFLP. In: K M Hui, J Bidwell, eds. Handbook of HLA typing techniques. Boca Raton: CRC Press, 1993; 9-70.
19 Kuwana M, Okano Y, Kaburaki J, Tsuji K, Inoko H. Major histocompatibility complex class II gene associations with anti-U1 small nuclear ribonucleoprotein antibody: relationship to immunoreactivity with individual constituent proteins. Arthritis Rheum 1995; 38: 396-405.

20 Earnshaw W C, Sullivan K F, Machlin P S, et al. Molecular cloning of cDNA for CENP-B, the major human cloning of cDNA for CENP-B, the major huma
centromere autoantigen. $f$ Cell Biol 1987; 104: 817-29.

21 Kuwana M, Medsger T A Jr, Wright T M. T cell response induced by DNA topoisomerase $I$ in patients with systemic sclerosis and healthy donors. $\mathcal{F}$ Clin Invest 1995 96: 586-96. 